\title{
INFLUÊNCIA FÍSICO-QUÍMICA DA FARINHA DE SOJA NO PROCESSAMENTO DE BISCOITO
}

Physical-chemical influence of soya flour in cookie processing influencia de físicoquímica de harina de soja en el procesamiento de cookies

\section{Susane Maciel de Souza ${ }^{2,3}$, Rômulo Alves Morais*1,2, Joenes Mucci Pelúzio $^{3}$, Maria Olivia dos Santos Oliveira ${ }^{1,2}$, Glêndara Aparecida de Souza Martins ${ }^{2}$}

${ }^{1}$ Programa de Pós-Graduação em Ciência e Tecnologia de Alimentos da Universidade Federal do Tocantins, Palmas - TO, Brasil.

${ }^{2}$ Laboratório de Cinética e Modelagem de Processos, Universidade Federal Tocantins, Palmas - TO, Brasil.

${ }^{3}$ Laboratório de Pesquisas Agropecuárias, Universidade Federal Tocantins, Palmas - TO, Brasil.

* Correspondência: Universidade Federal do Tocantins (UFT), Câmpus de Palmas, Avenida NS 15, Quadra 109 Norte/ Plano Diretor Norte Bloco II, sala 35B, Palmas/TO, CEP: 77001-090. e-mail:

alvesromulo2505@gmail.com

Artigo recebido em 29/04/2019 aprovado em 03/05/2019 publicado em 16/06/2019.

\section{RESUMO}

A crescente demanda por alimentos ricos em compostos funcionais, como proteínas e fibras vem ganhando grande relevância. Nesse contexto, este trabalho teve como objetivo testar a efetividade físico-química, com substituição parcial e integral de farinha de trigo por farinha de soja. Para realização do experimento foi preparado cinco formulações de biscoito com diferentes teores de farinha de trigo e farinha de soja de duas cultivares. O planejamento experimental adotado foi um fatorial de $2 \times 5$ com 10 tratamentos, sendo dois genótipos com cinco formulações e três repetições. As formulações contendo farinhas sucedâneas ao trigo apresentaram bom rendimento, maior teor de cinzas, proteínas, lipídios e fibras. Sendo a M8349 com maiores resultados dentre estas características citadas, já para a formulação com maior quantidade de trigo obteve maiores rendimentos para carboidratos. Assim, o enriquecimento do biscoito com a incorporação de farinha mista de soja e trigo é viável, proporcionando enriquecimento nutricional das formulações.

Palavras-chave: farinha, soja, trigo.

\section{ABSTRACT}

The growing demand for foods rich in functional ingredients, such as protein, and fiber, is gaining an importance. In this context, this work had as objective to test physical-chemical effectiveness, with partial and integral substitution of wheat flour for soybean meal. For the accomplishment of the experiment five biscuit formulations with different contents of wheat flour and soy flour of two cultivars were prepared. The experimental design was the $2 x 5$ factorial with 10 treatments, two genotypes with five formulations and three replicates. The formulations containing wheat flour as substitute showed good yield, higher content of ash, protein, lipids and fibers. Being the M8349 with higher results among these characteristics, already for the formulation with greater amount of wheat obtained higher yields for carbohydrates. Thus, the enrichment of the biscuit with the incorporation of mixed flour of soybean and wheat is feasible, providing nutritional enrichment of the formulations.

Keywords: flour, soy, wheat.

\section{RESUMEN}

La creciente demanda de alimentos ricos en compuestos funcionales, como las proteínas y las fibras, ha ganado gran relevancia. En este contexto, este trabajo tuvo como objetivo probar la efectividad físico-química, con 
sustitución parcial e integral de harina de trigo por harina de soja. Para la realización del experimento se preparó cinco formulaciones de galleta con diferentes niveles de harina de trigo y harina de soja de dos cultivares. La planificación experimental adoptada fue un factorial de $2 \times 5$ con 10 tratamientos, siendo dos genotipos con cinco formulaciones y tres repeticiones. Las formulaciones que contienen harinas sucedáneas al trigo presentaron buen rendimiento, mayor contenido de cenizas, proteínas, lípidos y fibras. Siendo la M8349 con mayores resultados entre estas características citadas, ya para la formulación con mayor cantidad de trigo obtuvo mayores rendimientos para carbohidratos. Así, el enriquecimiento de la galleta con la incorporación de harina mixta de soja y trigo es viable, proporcionando enriquecimiento nutricional de las formulaciones.

Descriptores: harina, soja, trigo.

\section{INTRODUÇÃO}

$\mathrm{O}$ consumo de alimentos funcionais e novos ingredientes aumentaram significativamente devido a vários fatores relacionados com a saúde e bem-estar. $\mathrm{Na}$ tentativa de potencializar o consumo desses produtos, várias alternativas têm sido propostas, dentre elas a inserção de novos ingredientes, que possam agregar valor nutricional ao alimento (BAÚ et al., 2012). Estes alimentos ditos como funcionais, tem gerado interesse por parte dos consumidores que pretendem inserir em sua dieta a incorporação de produtos ricos em componentes diversos (TROMBINI, 2013).

Diversas pesquisas vêm abordando a produção destes alimentos formulados, nos quais se procuram substituir total ou parcial, ingredientes como a farinha de trigo, por farinhas sucedâneas, como a farinha de soja, fécula de mandioca e quinoa. (VIEIRA, et al., 2015). Segundo a RDC No 263, de 22 de Setembro de 2005, farinha são os produtos obtidos de partes comestíveis de uma ou mais espécies de cereais, leguminosas, frutos, sementes, tubérculos e rizomas por moagem e ou outros processos tecnológicos considerados seguros para produção de alimentos (BRASIL, 2005).

A RDC 263 determina ainda que, biscoitos são produtos obtidos pela mistura de farinha(s), amido(s) e ou fécula(s) com outros itens, submetidos a processos de amassamento e cocção, fermentados ou não (BRASIL, 2005).
Nesse contexto, a soja se destaca devido às suas propriedades funcionais na indústria de alimentos, pois exercem ações moduladoras em determinados mecanismos fisiológicos por meio de suas propriedades funcionais (CIABOTTI et al., 2006). Segundo Vasconcelos et al. (2006), a adição do farelo de aveia e de farinha de soja eleva o teor de fibras, sendo um indicativo para sua classificação como fonte alimentar com "alto teor de fibras" e ou "alimento funcional". Sendo assim, este trabalho teve como objetivo analisar as alterações físico-químicas decorrente do enriquecimento de biscoitos, com farinha de soja.

\section{MATERIAIS E MÉTODOS}

\section{Matéria Prima}

O experimento foi realizado no Laboratório de Cinética e Modelagem de processos, situado na Universidade Federal do Tocantins. As duas variedades de soja BMX Desafio e M8349, foram disponibilizadas de um experimento realizado na UFT, campus de Gurupi- TO. As demais matérias-primas como: açúcar, margarina e farinha de trigo, necessárias ao processamento do biscoito, foram adquiridas em supermercados locais da cidade de Palmas-TO.

\section{Preparo da farinha}

Os grãos de soja foram triturados, em seguida foi realizada a secagem em estufa a temperatura de 105 ${ }^{\circ} \mathrm{C}$ por cinco horas, até que atingisse resultados entre $2 \%$ e $14 \%$ de umidade, para cada variedade. Onde, segundo a Resolução - CNNPA no 12, de 1978, farinha 
é o produto obtido pela moagem da parte comestível de vegetais, podendo sofrer previamente processos tecnológicos adequados tendo assim uma porcentagem entre $2 \%$ e $14 \%$ de umidade.

Para a obtenção dos biscoitos foi proposto um delineamento experimental, descrito na tabela 2, nas proporções soja e farinha de trigo. Os demais ingredientes foram utilizados nas mesmas quantidades em todas as formulações.

Tabela 1. Delineamento experimental com formulações do biscoito, variedade de soja e percentual de substituição (Soja/Trigo).

\begin{tabular}{ccc}
\hline Formulação & $\begin{array}{c}\text { Variedade de } \\
\text { Soja }\end{array}$ & $\begin{array}{c}\text { Percentual de } \\
\text { substituição (\%) }\end{array}$ \\
\hline F1 & BMX DESAFIO & $0 / 100$ \\
F2 & BMX DESAFIO & $40 / 60$ \\
F3 & BMX DESAFIO & $50 / 50$ \\
F4 & BMX DESAFIO & $60 / 40$ \\
F5 & BMX DESAFIO & $100 / 0$ \\
F1 & M8349 & $0 / 100$ \\
F2 & M8349 & $40 / 60$ \\
F3 & M8349 & $50 / 50$ \\
F4 & M8349 & $60 / 40$ \\
F5 & M8349 & $100 / 0$ \\
\hline
\end{tabular}

\section{Processamento do biscoito}

Para o processamento dos biscoitos, houve a mistura manual dos ingredientes como açúcar, ovo, água, margarina e as farinhas em suas variadas proporções até a homogeneização da massa. Em seguida os biscoitos preparados foram assados em forno elétrico.

\section{Análises físico-químicas}

As análises de umidade, lipídios, proteínas, fibras e cinzas foram realizadas conforme descrito pelo Instituto Adolf Lutz (2008). Com exceção de carboidratos que foi calculado por diferença. Sendo que as mesmas análises foram realizadas para caracterização da farinha e dos biscoitos processados, ambas realizadas em triplicata.

\section{Estatística}

Os resultados obtidos através das análises físico-químicas foram submetidos a teste de análise de variância (ANOVA), seguido do teste de Tukey para comparação de médias entre as cultivares dentro de cada formulação ao nível de 5\% de significância.

\section{RESULTADOS E DISCUSSÃO}

A análise de variância para teores de proteínas, lipídeos, cinzas, fibras e carboidratos (Tabela 2) mostrou efeito significativo para as cultivares e para a interação de cultivar x formulação. Os coeficientes de variação tiveram índices pequenos, dando assim maior confiabilidade aos resultados obtidos.

Tabela 2. Resumo das análises de variância das características de proteína, lipídeo, cinzas, fibras e carboidratos de duas cultivares de soja em cinco formulações de biscoitos contendo farinha de soja 2015/2016.

\begin{tabular}{|c|c|c|c|c|c|c|}
\hline \multirow[t]{2}{*}{ FV } & \multirow[t]{2}{*}{$\mathbf{G L}$} & \multicolumn{5}{|c|}{ QM } \\
\hline & & Proteínas & Lipídios & Cinzas & Fibras & Carboidratos \\
\hline Cultivar & 1 & $1.43008^{*}$ & 2.88920 * & $0.00533^{*}$ & $3.55869^{*}$ & $22.51410^{*}$ \\
\hline $\begin{array}{c}\text { Formulação } \\
\text { Cultivar }\end{array}$ & 4 & 86.55858 & 60.61448 & 5.15982 & 16.84360 & 533.99098 \\
\hline $\begin{array}{c}\mathbf{x} \\
\text { Formulação }\end{array}$ & 4 & $0.23237^{*}$ & $0.17501^{*}$ & $0.11921^{*}$ & $0.49128^{*}$ & $2.09803^{\star}$ \\
\hline $\begin{array}{l}\text { Média } \\
\text { CV(\%) }\end{array}$ & & $\begin{array}{c}14.41567 \\
0.35\end{array}$ & $\begin{array}{c}14.97967 \\
0.32\end{array}$ & $\begin{array}{c}1.85600 \\
1.11\end{array}$ & $\begin{array}{c}3.82695 \\
1.14\end{array}$ & $\begin{array}{c}62.14158 \\
0.17\end{array}$ \\
\hline
\end{tabular}

* Significativo ao nível de 5\% de significância 
Foi realizado um desdobramento com o intuito de detectar diferenças significativas entre as formulações de todas as características analisada, para as duas cultivares. Os teores de proteína para as cincos formulações estudada são mostradas na tabela 3.

Tabela 3. Teores de proteínas, lipídios, cinzas, fibras e carboidratos com cinco formulações de farinha de duas cultivares de sojas diferente.

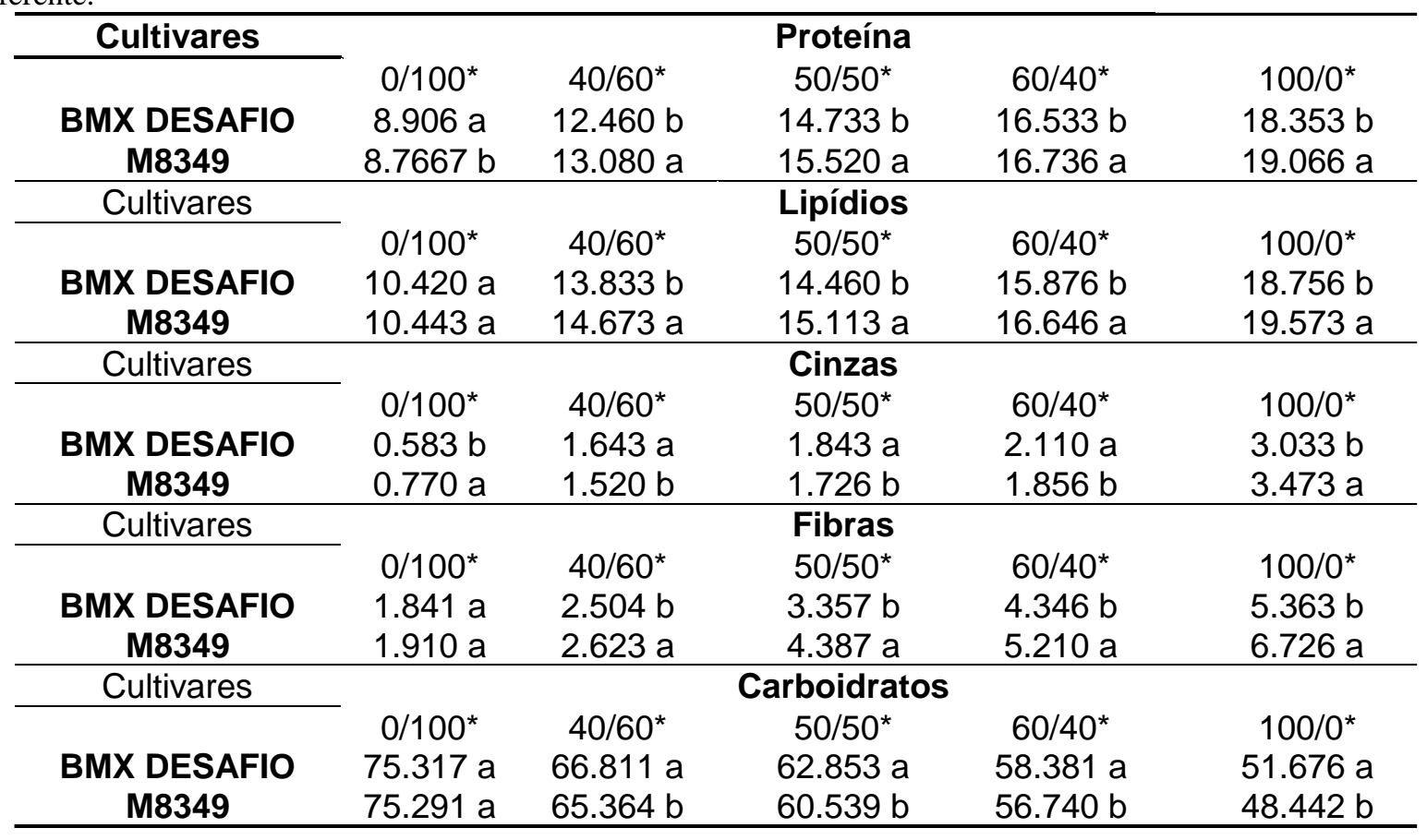

Médias seguidas pela mesma letra na coluna não se diferem estatisticamente entre si pelo teste de Tukey ao nível de 5\% de significância; *Formulações (soja/trigo)

Entre as cultivares analisadas, a M8349 foi a que obteve um maior índice de proteína em quase todas as formulações, com valores entre $8 \%$ e $20 \%$, em contrapartida as duas variedades duplicaram o valor protéico nas formulações contendo maiores quantidades de farinha de soja, tendo assim resultados de $16,73 \%$ e $19,06 \%$ respectivamente, em comparação a primeira formulação, que tem fração apenas de farinha de trigo.

Nesse contexto, a percentagem de proteína cresce com o aumento da concentração de farinha de soja presente na formulação, isso se dá devido à soja conter grande quantidade de proteínas, na qual Silva, et al. (2006) relatam que o grão de soja apresenta $40 \%$ de proteína em sua composição. Resultados semelhantes são apresentados por Yoshida, et al.
(2014) onde os autores comparam biscoitos tipo cookies com formulações contendo diferentes teores de farinha de trigo e de soja, sendo possível perceber que o aumento da proporção da farinha de soja elevou os valores de proteína.

Com relação aos teores de lipídios a cultivar M8349, se destacou em todas as formulações, obtendo resultados entre $10 \%$ para a formulação que continha apenas farinha de trigo e em torno de $13 \%$ a $18 \%$, para aquelas com adição de farinha de soja. Observou-se também que, na formulação contendo $100 \%$ de farinha de trigo não houve diferença estatística entre as cultivares ao nível de 5\% de significância, podendo este fator, ser atribuído ao fato de a formulação conter a mesma quantidade de farinha de trigo dentre os 
outros ingredientes e por não ter qualquer quantia de farinha de soja.

Para o teor de lipídios (Tabela 03) houve um acréscimo, entre as formulações para as duas cultivares estudadas de acordo com o aumento da quantidade de farinha de soja. Nesse sentido Dantas, et al. (2009) também observaram o aumento na taxa de lipídios, com o aumento da concentração de farinha de soja em pães, na qual ele mostra que este aumento, provavelmente favoreceu o perfil de ácidos graxos essenciais, onde os pães de soja apresentaram um aumento em torno de $7 \%$ em relação ao pão convencional.

Quanto ao teor de cinzas a M8349 obteve maiores valores em quase todas as formulações, com exceção da que continha $40 \%$ de trigo e $60 \%$ de farinha de soja, ao qual a BMX DESAFIO teve um resultado de $1,64 \%$ (Tabela 3 ), na qual se observa o aumento do teor de cinzas conforme se aumenta as concentrações de farinha de soja, tanto para uma cultivar quanto para outra. Hoffpauer (2005) salienta que as cinzas de um determinado alimento indicam o resíduo orgânico que mantém após a queima da matéria orgânica. Nesse sentido, Vieira et al. (1999) destacam que, a farinha de soja possui quantia expressiva de minerais como fósforo, magnésio, potássio e ferro, o que justifica o fato de os biscoitos feitos com maiores teores de farinha de soja conterem maiores índices de cinzas.

Para os teores de fibras não houve diferença significativa entre as variedades na formulação contendo $100 \%$ de farinha de trigo, pois foram utilizadas as mesmas quantidades de ingredientes. Sendo que os biscoitos formulados com as duas cultivares teve um aumento no teor de fibras variando de $1,91 \%$ a $7 \%$. Fato também constatado por Carvalho et al. ao analisar 6 cultivares de soja mostrou elevados valores de fibras variando entre $5 \%$ e $10 \%$, comprovando assim o que já foi dito.
Para os teores de carboidratos existe uma relação entre a quantidade de carboidrato e a quantidade de farinha de trigo presente nas formulações, ou seja, o percentual de carboidratos diminui à medida que a farinha de soja é incorporada. Nesse sentido Perez et al. (2007) obteve resultados semelhantes ao analisar biscoitos adicionando-se 10\%, $15 \%$ e $20 \%$ de farinha de berinjela, uma vez que os autores obtiveram valores de carboidratos decrescentes $(62,31 \mathrm{~g} / 100 \mathrm{~g}, \quad 59,40 \mathrm{~g} / 100 \quad \mathrm{~g} \quad \mathrm{e}$ $55,49 \mathrm{~g} / 100 \mathrm{~g}$ ) à medida que a farinha de trigo foi substituída pela de berinjela.

\section{CONCLUSÃO}

Os biscoitos elaborados com elevados índices de farinha de soja apresentaram maiores teores de lipídeos, proteínas, cinzas e fibras, enquanto o carboidrato teve um alto índice para a formulação contendo $100 \%$ de farinha de trigo, devido este ser mais rico em amido que a soja. A cultivar que apresentou melhores resultados para todas as características, em quase todas as formulações foi a M8349.

Todos os autores declararam não haver qualquer potencial conflito de interesses referente a este artigo.

\section{REFERÊNCIAS}

BAÚ, T.R.; SILVA, L.C.; GARCIA, S.; IDA, E.I. Propriedades funcionais tecnológicas das fibras de soja, aveia e trigo e produtos de soja com adição de fibras e fermentados com cultura de kefir. Semina: Ciências Agrárias, v.33, n.2, p.3093-3102, 2012.

BRASIL. Ministério da Saúde. RDC n ${ }^{\circ} 263$, de 22 de setembro de 2005: Aprova o "regulamento técnico para produtos de cereais, amidos, farinhas e farelos", constante do Anexo desta Resolução. Diário Oficial da União, Brasília, p.5, 2005.

CIABOTTI, S.; BARCELLOS, M.F.P.; MANDARINO, J.M.G.; TARONE, A.G. Avaliações químicas e bioquímicas dos grãos extratos e tofus de 
soja comum e de soja livre de lipoxigenase. Ciência Agrotecnológica, v.30, n.5, p.920-929, 2006.

CARVALHO, M.R.B.; STECH, M.R. Avaliação da composição centesimal e das atividades dos fatores antinutricionais em diferentes cultivares de soja. Boletim Instituto da Pesca, 24 ( ${ }^{\circ}$ especial), p.139145, 1997.

DANTAS, M.I.S.; ANDRADE, G.F.; PIOVESAN, N.D.; MARTINO, H.S.D. Farinhas mistas de trigo e de soja agregam valor nutricional e sensorial em pães. Revista Instituto Adolfo Lutz, v.68, n.2, p.209-214, 2009.

HOFFPAUER, D.W. New applications for whole rice bran. Cereal Foods World,50 (4), p.173-174, 2005.

Instituto Adolfo Lutz. Métodos físico-químicos para análise de alimentos. (4ed.) Brasília: ANVISA, 2008.

PEREZ, P.M.P.; GERMANI, R. Elaboração de biscoitos tipo salgado, com alto teor de fibra alimentar, utilizando farinha de berinjela (Solanum melongena, L.). Ciência e Tecnologia de Alimentos, v.27, n.1, p.186-192, 2007.

SCHEUER, P.M.; FRANCISCO, A.; MIRANDA, M.Z.; LIMBERGER, V.M. Trigo: Características e utilização na panificação. Revista Brasileira de Produtos Agroindustriais, v.13, n.2, p.211-222, 2011. TROMBINE, F.R.S.; LEONEL, M.; MISCHAN, M.M. Desenvolvimento de snacks extrusados a partir de misturas de farinha de soja, fécula e farelo de mandioca. Ciência Rural, v.43, n.1, p.178-184, 2013.

VASCONCELOS, A.C.; PONTES, D.F.; GARRUTI, D.S.; SILVA, A.P.V. Processamento e aceitabilidade de pães de forma a partir de ingredientes funcionais: farinha de soja e fibra alimentar. Alimentação e Nutriçãa, v.17, n.1, p.43-49, 2006.

VIEIRA, C.R.; CABRAL, L.C.; PAULA, A.C.O. Composição centesimal e conteúdo de aminoácidos, ácidos graxos e minerais de seis cultivares de soja destinadas à alimentação humana. Pesquisa agropecuária Brasileira, v,34, n.7, p.1277-1283, 1999.

VIEIRA, T.S.; FREITAS, F.V.; SILVA, L.A.A.; BARBOSA, W.M.; SILVA, E.M.M. Efeito da substituição da farinha de trigo no desenvolvimento de biscoitos sem glúten. Brazilian Journal of Food Technology, v.18, n.4, p.285-292, 2015.

SILVA, M.S.; NAVES, M.M.V.; OLIVEIRA, R.B.; LEITE, O.S.M. Composição química e valor protéico do resíduo de soja em relação ao grão de soja. Ciência e Tecnologia de Alimentos, v.26 n.3, p.571-576, 2006.

YOSHIDA, B.Y. PEREIRA, D.G. CASTILHO, S. P.G. SEIBEL, N.F. Produção e caracterização de cookies contendo farinha de okara. Jornal Food Nutrition, v.25, n.1, p.49-54, 2014. 